Clinical Research at University College Hospital Medical School, London, made important contributions to cardiovascular medicine. But it was Sir Thomas Lewis, a man in advance of his age, who trained a generation of research workers in the application of scientific method to clinical problems, and these men became available in the 1930 's, when methods of clinical research were being elaborated. The Ccuncil itself established clinical research units and it is now spending more than $£ 400,000$ a year on investigations directly concerned with patients. When the National Health Service Acts gave virtually all facilities for clinical research to the Health Departments, close liaison and unanimous agreement were established between these Departments and the Medical Research Council. It is now proposed that there should be a central organization for the promotion of clinical research, which should be a part of the Medical Research Council, that provision should be made for decentralized research with the greatest possible freedom from supervision and that careers in clinical research should be equated with careers in the National Health Service.

The main interest of scientific readers of this report will no doubt be in the section of it entitled "Some Aspects of Medical Research", which reviews the results obtained by the Council's workers in certain fields. Dr. A. J. P. Martin, of the Division of Physical Chemistry, National Institute for Medical Research, and Dr. R. L. M. Synge, of the Division of Biochemistry, Rowett Institute, Aberdeen, have been jointly awarded the Nobel Prize for chemistry for 1952 for their work on partition chromatography. This section of the report gives an interesting account of the development of chromatography since 1906. Mental deficiency is discussed and the impressive work of the Council's Research Unit on Occupational Psychiatry is described. The Council's work on the causes of maternal and child mortality and on the social aspects of this important subject has as its ideal a pregnant mother who feels well and has a spontaneous and easy labour and gives birth to a lusty child which she is able to feed successfully, and the results obtained have done more for the nation than many people realize. The importance of the glands which produce internal secretions has long been recognized, and the Council's workers at Cambridge who have been studying the close relationships between the central nervous system and the posterior pituitary gland during lactation have shown that the action of sucking excites a nervous reflex in the mother which causes secretion by the posterior pituitary gland and the liberation of a hormone which acts on the mammary glands and causes the 'let down' or ejection of milk. The oxytocic hormone is the most powerful in this respect, and this hormone also stimulates the contraction of the uterine muscle. This work thus provides an explanation of the age-old observation that suckling the young helps the contraction of the uterus after labour. The Cambridge workers are also studying the anterior pituitary gland and the control of the secretion of corticotrophin by this gland.

The section of the report mentioned above also considers work on bacterial food poisoning, the development by bacteria of resistance to drugs, the etiology, mechanism and diagnosis of hæmophilia, hearingaids and diseases of the ear, the thyroid gland and the uses of radioactive iodine in medicine, the epidemiology, pathology and treatment of poliomyelitis, the physiology of the red blood cells, each of which lives for an average period of 120 days, the synthesis of porphyrins and hæmoglobin in the body and the formation of bile pigment.

The rest of the report provides details of the various units of the Medical Research Council, the names of their staffs and bibliographies of papers published by them and by members of that valuable organization, the Public Health Laboratory Service, and by workers in the Institute of Cancer Research.

All those who work for the Council, whether they are members of the Council itself or are research workers, or perform those unpublicized but highly skilled tasks upon which all modern scientific research depends, deserve the gratitude of the public for whose health and welfare all this devoted work is so patiently and efficiently done. G. LAPAGE

\section{SCIENCE AND FREEDOM}

$7 \mathrm{HE}$ International Congress of Science and Freedom held a meeting in Hamburg during July 23-26, which was attended by more than one hundred delegates from nineteen countries, including fourteen from the United Kingdom. The purpose of the meeting was to discuss the danger to cultural freedom which has arisen in totalitarian countries, especially those behind the Iron Curtain. The delegates, among whom were four Nobel laureates, included leading representatives of other branches of learning in addition to science.

The opening session in the Rathaus was addressed by Dr. Max Brauer, mayor of Hamburg, Prof. Bruno Snell, rector of the University, Prof. Denis de Rougemont (Geneva), president of the executive committee of the Congress for Cultural Freedom, Prof. James Franck (Chicago), Prof. J. Pieper (Münster) and Prof. Max Hartmann (Tübingen). The twenty communications which were considered during the meeting included papers by Prof. Michael Polanyi (Manchester) on pure and applied science and their appropriate forms of organization; Dr. J. R. Baker (Oxford) on scientific authority and the system of scientific publications; Prof. S. K. Allison (Chicago) on requirements of security and academic freedom; Prof. T. Dobzhansky (New York) on biology in the U.S.S.R.; Prof. G. v. Rauch (Marburg) and Prof. V. Gitermann (Zurich) on history in the U.S.S.R.; and five papers devoted to "Neutrality or Profession of Faith" and "Moral Responsibility and Science". The various communications aroused much discussion, and it was often difficult for the respective chairmen to keep the speakers to the prescribed time limits.

It was generally agreed that totalitarianism to-day constitutes the greatest and most potent threat to cultural freedom, and the infiltration of Communist ideas into the circles of academic teachers and students has often given rise to a general distrust of the universities as seed-beds of intellectual insubordination. This has led frequently to the demand that universities should recognize without question existing economic and social systems in their respective countries.

The independent position of universities has been further impaired by the fact that they have become increasingly dependent on government grants. These tend to foster those fields of science in which some practical or economic advantage is to be expected. In addition, the Second World War has resulted in the suppression or corruption of many of the older 
universities of Europe, with their deeply rooted traditions of academic freedom. This has very seriously diminished the sense of cultural obligation among the public to support the progress of pure science, and it has become rare nowadays to bear the head of a university appealing for funds for the advancement of knowledge as an end in itself.

At the final meeting it was agreed to issue the following message : "At the conclusion of this International Conference in Hamburg on Science and Freedom in which more than 100 scientists and scholars from 19 countries have discussed the theoretical and practical problems of scientific research today, we should like to convey our fraternal greetings to our fellow-scientists separated from us by political power. We are convinced that these, our unhappy colleagues, have never ceased to feel a profound loyalty to those ideals of free inquiry without which science itself would never have arisen. We look forward to the day when they can sit down with us as free men at such a conference as this, to discuss our common problems in a spirit of sincerity and objectivity that they must surely cherish under the most difficult circumstances".

Edward Hindle

\section{ERUPTIVE PROMINENCE OF FEBRUARY 26, 1953, AND ASSOCIATED RADIO NOISE-BURST}

$\triangle$ FTER a period of rather pronounced inactivity A characteristic of the present minimum phase of the sunspot cycle, an interesting type of activity occurred on February 26. On the previous day a rather insignificant-looking prominence had been observed on the north-east limb at a mean latitude of $40^{\circ}$. On the morning of February 26 visual observations with the spectrohelioscope and photographs obtained with the spectroheliographs between $0200 \mathrm{hr}$. and $0400 \mathrm{hr}$. U.T. showed that the prominence had grown somewhat in height and had also extended southwards to about lat. $30^{\circ}$. 'There was, however, nothing unusual in this, for this increase in size could
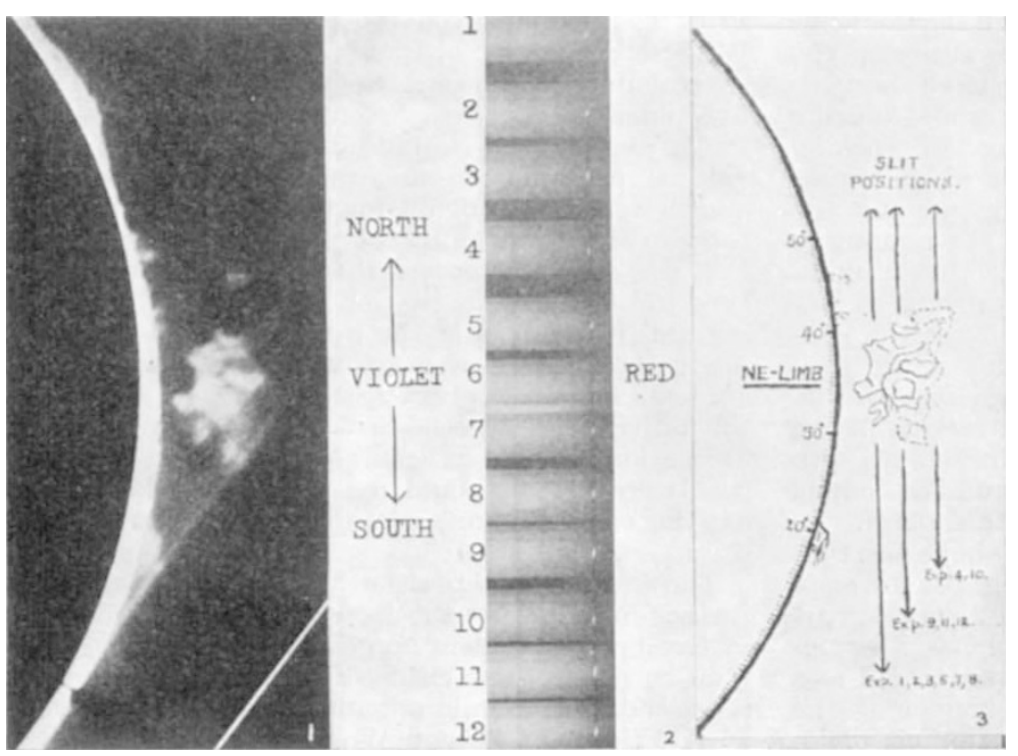

Tigs. 1-3 easily be regarded as the coming into view of parts of the prominence previously behind the limb. There was no visible sunspot in the neighbourhood of the prominence; but the spectroheliograms taken on February 28 and March 1 showed a plage faculaire around lat. $22^{\circ}$. Observations during the early hours (0200-0400 hr.) of February 26 showed that the prominence was of the quiescent type.

Between $0400 \mathrm{hr}$. and $0430 \mathrm{hr}$. there was no certain sign that the prominence was working up for an eruption, although some slight agitations were noticeable. However, a control observation with the spectrohelioscope at $0500 \mathrm{hr}$. revealed a very different picture : the height of the prominence had grown to $150^{\prime \prime}$, or about double its previous height, and large Doppler displacements were also apparent. At the base the Doppler shifts measured were I.2 A. towards red (about $55 \mathrm{~km}$. $/ \mathrm{sec}$.), while the top portions of the prominence were showing displacements of $1.4 \mathrm{~A}$. towards the violet (about $65 \mathrm{~km}$. $/ \mathrm{sec}$.). Until $0507 \mathrm{hr}$. the prominence was still adhering to the sun's surface; but from $0510 \mathrm{hr}$. it broke off from the limb and the next $30 \mathrm{~min}$. saw the most active phase of the eruption. Some parts of the prominence reached a height of $260^{\prime \prime}$, and the maximum Doppler displacement observed in some parts was of the order of $6 \mathrm{~A}$. to red $(270 \mathrm{~km}$. $/ \mathrm{sec}$.). The eruption reached its peak by $0545 \mathrm{hr}$., after which the prominence-a compact mass until then-began to disintegrate. Two welldeveloped streamers could be seen descending from the eruptive mass to the sun's surface and exhibiting Doppler shifts of 3-4 A. to violet (135-180 km./sec.), where they met the limb. The ejected prominence matter was apparently being forced back to the sun's surface at lat. $22^{\circ}$ through these streamers. By $0700 \mathrm{hr}$. it became difficult to identify clearly the prominence and its streamers, and in another halfhour the whole phenomenon had subsided leaving no trace of the prominence. From the above description of the course of events this eruptive prominence would probably be classed best as a 'surge' of Class IIId in Pettit's classification, although it was not visibly associated with a sunspot group.

Luckily the prominence was so located that the spectrohelioscope slits were almost exactly tangential to the part of the limb where the prominence was. As our spectrohelioscope has no arrangement for rotating the image, this circumstance made it possible to take spectrograms at definite heights in the prominence with the help of the camera ${ }^{1}$ attached to the side of the spectrohelioscope. Altogether twenty spectrograms were secured in the $H_{a}$ region with exposure times of 2-4 sec. each. The first twelve of these were obtained between 0535 $\mathrm{hr}$. and $0545 \mathrm{hr}$. while the prominence was moving away from the limb as a fairly compact mass (Fig. 1). The other eight spectra were photographed between 0620 and $0625 \mathrm{hr}$. with the first slit of the spectrohelioscope cutting across the two streamers; although these spectra also give some interesting information, we shall not consider them in the present communication. The first twelve exposures (Fig. 2) reveal interesting details concerning the 